\title{
Achieving reliability and energy savings in operate of pumping stations
}

\author{
Oleg Glovatskii ${ }^{1}$, Jaloliddin Rashidov ${ }^{2 *}$, Boybek Kholbutaev $^{3}$, and Khayrullo Tuychiev ${ }^{2}$ \\ ${ }^{1}$ Research Institute of Irrigation and Water Problems, Tashkent, Uzbekistan \\ ${ }^{2}$ Tashkent Institute of Irrigation and Agricultural Mechanization Engineers, Tashkent, Uzbekistan \\ ${ }^{3}$ Jizzakh Polytechnic Institute, Jizzakh, Uzbekistan
}

\begin{abstract}
Hydromechanical equipment of pumping stations of irrigation systems, including the main equipment of pumping stations of the AmuBukhara machine channel, was taken as the object of research. The study aims to assess the operating conditions of pumping stations and improve the main units' reliability by developing new units that ensure reliable and resource-saving operations. An important consequence of using new elements of irrigation systems during reconstruction is an increase in the unit capacity of regulated pumping units, which gives additional energy savings and reduces technological costs by $15-20 \%$. The practical significance of the research results is based on the developed methods of hydraulic calculation of the flow in the flow section of the pumps, the assessment of reliability during operation under various conditions of the quality of the pumped water, and the criteria of its state.
\end{abstract}

\section{Introduction}

As you know, creating a network of irrigation in the arid zone is associated with the development of an irrigation machine. Safety of operation of pumping stations (PS) can be achieved by implementing the set of conditions, ensuring minimum impact on the external pump units (PU) related to the state of water resources and the impact of the PU themselves on environmental objects. Because ultimately, the construction and operation of the entire complex hydraulic structures are carried out to manage water resources to improve people's quality of life $[1,2]$.

Among the conditions of safety of operation of the complex include:

- The amount of water needed for the sustainable functioning of the structures related to water consumption. Violation of the PU's efficiency, caused by a shortage of water resources, directly affects the reception of food and other components of the quality of life of the population. Particularly acute, this problem in the Republic, where much of the water sources is transboundary waters $[3,4]$.

\footnotetext{
* Corresponding author: jaloliddin5@mail.ru
} 
- High-quality water resources. The functioning of the PU of resistance affects the chemical composition and properties of water. When the consumption of water in the various processes may be a failure of the material with which it is in contact.

When operating in the PU enters water sources, as is commonly believed, the regulatory clean water, with a high-temperature regime. However, water is contaminated with oils, fin, dust, mineral products. Even if their water content does not exceed the maximum permissible concentration norms and other regulatory indicators, it may be damaged the ecological status of water bodies. Fever causes direct damage to the state of the reservoir and hydromechanical equipment of pumping stations $[5,6]$.

- Minimizing the risk of exposure to the operation of the PU on the environment objects. It risks the number, the impact on the environment and entailing negative social and environmental impacts include: yield land of order, suitable for different activities, depending on the priorities in the area (cultivation of agricultural products, various kinds of crafts), the impact on the traditional way life conflict situations involving the use of water and energy resources.

There are regulations governing exposure to corrosive water and suspended solids in the water. However, there are no standards for the content of other substances in the water acting on the PU elements, depending on the types of materials.

\section{Methods}

When performing the work, the methods of hydraulic study of the flow structure in the nodes of pumping stations were used to ensure the normal functioning of the hydromechanical equipment of the PS based on well-known measurement methods. The research methodology was refined in the process of imitating the study of hydraulic processes corresponding to different operating modes $[3,7]$. The reliability of the data obtained in the course of theoretical research was proved by mathematical methods of checking the adequacy of the results of experiments and field studies during the operation of pumps [8].

\section{Results and Discussion}

Every year, the PU of irrigation systems in the Republic consumed up to 7-8 bln. KW / h, not counting the diesel fuel. Reducing the power consumption for the PU up to about 10$15 \%$ is possible, mainly due to power management systems, water lifting machines (WLM). Due to the sharp rise in prices and the growing scarcity of energy resources to the fore, the problem of reducing their consumption of the PU. Lack of priority works on this problem makes it impossible to optimize the PS mode at the present level of exploitation.

The main reasons for this are:

- high content of abrasive particles and fin in the pumped water, harsh climatic conditions associated with high-temperature water and air;

- large size and water flow rate in the flow path elements, large water supply, and electric power units, the complex transition processes accompanying their operation;

- structural disadvantages of hydraulic machines and hydraulic structures, including non-effective technical water supply system;

- imperfect organizational and technical level of operation of pumping units and structures, science-based methodology, regulatory and other technical document management workflow water lifting and environmental conditions of the equipment and operating personnel. 
The need for energy-efficient pumping systems is usually justified by technological and economic factors, currently identified environmental aspects. Large pumping stations are very energy-intensive facilities. They annually spend about $20 \%$ of electricity generated, that the CIS Republics is about 300 billion $\mathrm{kWh}$ per year. Electricity production has an adverse effect on the environment [9]. With an annual growth of electricity generation in the $3-4 \%$ of the commissioning of new generating capacity resulting from energy-saving mode to the PU may be reduced to $1 / 3$. As a result, the burning of 1.8-2 million tons of fuel equivalent, or 2-3 million tons of coal, will be prevented real. This will provide significant environmental benefits by reducing harmful emissions into air and water. Furthermore, these systems reduce the probability of occurrence of pressure shocks, prevent the destruction of pipelines, and, consequently, the spout to the surface water and in water. An important consequence of the application systems in the reconstruction is to increase unit capacity-controlled pumps that provide additional energy savings and reduces the amounts of PS technology buildings by $15-20 \%$. At the same time, the land is released for other purposes, for example, to increase green areas $[2,3]$. The main difficulty in planning energy-saving mode is to construct an adequate mathematical model of the current system. Identification of the model is carried out by successive approximations using the results of field measurements of WLM resource costs.

Further work is underway in the following areas:

- Expansion and identification of water-supply design scheme PU node structures;

- Development of management options WLM with the introduction of the scheme in new media management and optimize the work of the PU members;

- organization of the system of operative information gathering and processing.

In practice, operation of the PU controlled $30-40 \%$ of the total number of parameters to be monitored, which will undoubtedly worsen the environmental aspects of the units as PS operating mode is changed following the schedule of water consumption and due to other factors. In general, the quality of the pumped water is characterized by a set of $\mathrm{n}$ parameters; concentration of suspended particles floating bodies, chemical properties, density, temperature, and others.

Combining these parameters forms an $\mathrm{n}$-dimensional vector $\mathrm{x}\left(\alpha_{1}, \alpha_{2}, \ldots \alpha_{m}\right)$ the quality of the pumped water (see Table.).

Table - Conditional evaluation of the quality characteristics of the pumped water at different criteria of its state:

\begin{tabular}{|c|c|c|c|}
\hline \multirow{2}{*}{$\begin{array}{c}\text { Condition of swapped } \\
\text { water }\end{array}$} & \multirow{2}{*}{$\begin{array}{c}\text { Estimation } \\
\text { Quality in } \\
\text { ball }\end{array}$} & \multicolumn{2}{|c|}{ Quality scores in water quality parameters } \\
\hline & & $\begin{array}{c}\text { Turbidity stream, } \\
\mathrm{kg} / \mathrm{m}^{3}\end{array}$ & $\begin{array}{l}\text { Saturation of the fin } \\
\text { flow }\end{array}$ \\
\hline Absolutely & 4 & to 0,5 & to 0,05 \\
\hline Clean & 3 & $0.5 \leq \rho<1.5$ & $0.05 \leq \delta<0.3$ \\
\hline Moderately polluted & 2 & $1.5 \leq \rho<3$ & $0.3 \leq \delta<0.6$ \\
\hline Strongly contaminated & 1 & more than 3 & more than 0,6 \\
\hline
\end{tabular}

We distinguish two main parameters: $\rho$ is turbidity stream; $\delta$ is saturation of the fin flow.

$$
\rho=\frac{R}{Q} ; \delta=\frac{W_{n \cdot M}}{W}
$$


where $\mathrm{R}$ is suspended sediment flow; $Q$ is water flow, $P S$ feed; $W_{n . m}$ is the amount of floating debris; $\mathrm{W}$ is the amount of runoff.

In recent years, there has been realized and a tendency to create small areas of local farmers irrigated plots. In this regard, possible growth of the applicability of the PU of mobile diesel driven. Being mobile pumping equipment for rapid creation (with minimal time and money) of the irrigation system and irrigation organizations are on site have no support structures, including ensuring environmental safety; settling a playground paved for ease of operation. However, the PU are the sources of pollution by hazardous substances - oil, as following its functional purpose, they are located directly on the banks of the water body that is located in the zone of the coastal security band, within which the existing legislative instruments set high requirements to protect water bodies from pollution to all activities [2, 9]. From an environmental point of view, most of the large pumps and diesel pump units especially type SNP-500/10 assessment experts, may be soon more dangerous because of the progressive deterioration of sealing knots and large leaks of petroleum products in the pumped water. To ensure the protection of surface and groundwater when applied to irrigation systems, diesel SNP can formulate the following environmental requirements:

1. Must be assessed environmental risk and possible contamination of the site and the scale of the water body, namely, determine the amount, types, and dynamics in time savings waste petroleum products, analyzed options for emergency use of petroleum products on the SNP and the estimated volumes of the spill.

2. On-site SNP should be provided to exclude the oil spill spreading beyond the technological platform, their collection system, capacity for temporary storage, and other devices that prevent the flow of oil into the water bodies.

3. The design of the outer part of the fuel system, cooling system, and lubrication should be tight, which is intended to prevent the flow of oil products and to get them to the soil, surface water, and groundwater. Since the oil consumption is approximately $6 \%$ of the fueling, the amount of lubricating material spilled during filling is mechanized $15 \ldots 20 \%$, and when unpowered $-5 \ldots 10 \%$ of the total fueling and lubricants [2]. Diesel fuel losses due to leaks in the fuel system connections are $0.1 \ldots 0.4 \%$ filling volume. During maintenance, the amount of pollution it is advisable to take a share of the total volume of polluting products - at a rate of 5\%. Environmentally the most dangerous emergency situation may occur if the diesel fuel in the fuel tank pours out completely. Oil spills partially infiltrate into the soil (at the site of the SNP stand to the water source), the rest will fall into it. In this case, the situation will be of catastrophic proportions for water sources, including the nature of evaporation due to the appearance of the surface film. The research object is hydromechanical equipment of pumping stations of irrigation systems, including hydromechanical equipment of pumping stations in the Amu-Bukhara canal, interception, and removal of suspended particles in water.

The scientific novelty of the research is as follows:

the method for determining the causes of failure of hydromechanical equipment of pumping stations based on a new structural-functional scheme has been improved;

improved methods for determining the probability state of hydromechanical equipment of pumping stations of the irrigation system;

The optimal parameters of the device working elements are determined based on analytical dependencies. The slurry is a mixture of solids and liquids. Its physical characteristics are dependent on many factors such as size and distribution of particles, the concentration of solids in the liquid phase, size of the conduit, level of turbulence, temperature, and absolute (or dynamic) viscosity of the carrier.

Theoretically, a single-phase liquid of low absolute (or dynamic) viscosity can be allowed to flow at slow speeds from a laminar flow to a turbulent flow. However, a twophase mixture, such as slurry, must overcome a deposition critical velocity or a viscous 
transition critical velocity. If the slurry's speed of flow is not sufficiently high, the particles will not be maintained in suspension [11,12].

The flow in a centrifugal pump is in a radial outward direction and shows research the 3 dimensional model of a centrifugal pump (figure 1).
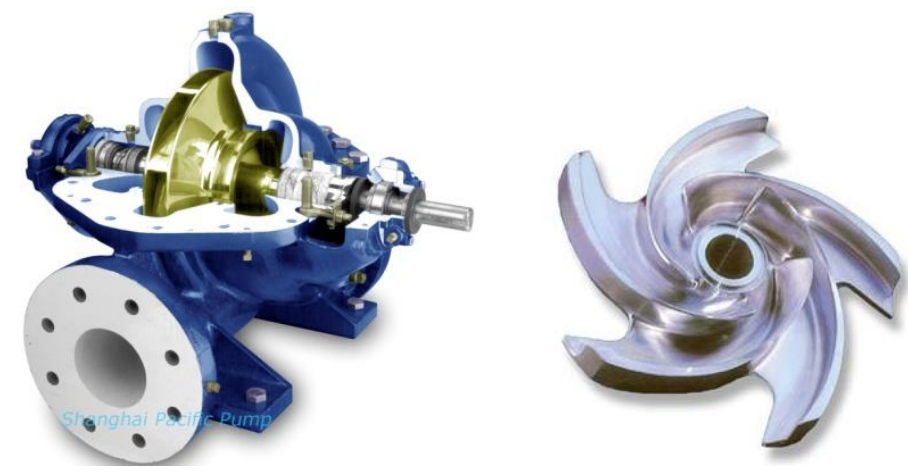

Fig. 1. 3D model of impeller centrifugal pump

The centrifugal pump works on the principle of forced vortex flow, which means that of forced vortex flow, which means that when an external flow rotates a certain mass of liquid, the rise in pressure head of the rotating liquid takes place $[13,14]$. The rise in pressure head at any point of the rotating liquid is proportional to the square of tangential velocity of the liquid at that point $[15,16]$. Thus, at the impeller outlet where the radius is more, the rise in pressure head will be more, and the liquid will be discharged at the outlet with highpressure head. (figure 2).
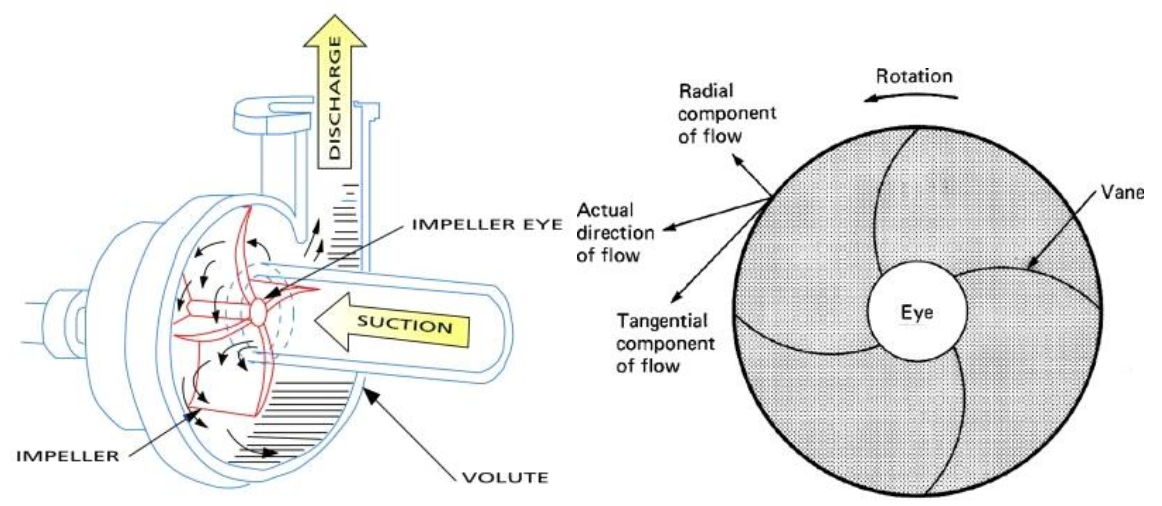

Fig. 1. Flow of fluid in a centrifugal pump

The probability of failure of the elements of pump units in the irrigation system based on the Ishikawa scheme and the Pareto diagram, recommendations at PS within the Interregional Amu-Bukhara machine channel. Predicting the possibility of breakage and due to their exclusion, an increase in the water supply of pumping stations by $12 \%$ was determined;

a device for cleaning and removing deposits detained by gratings installed in front of the vestibule was developed and introduced at the PS Amu-Bukhara-2. As a result, it became possible to exclude the water supply, achieve normal depth in the vestibule, prevent the operation of pumping devices in cavitation mode and increase the service life of pumping 
units by 1.2-1.3 times [2, 4]. As a result of research and development due to the improvement of the process of delay and removal of deposits reaching the pumping station, it is possible to reduce labor costs by $30.6 \%$ and increase economic efficiency by $27.5 \%$.

\section{Conclusions}

It is recommended to use the developed dependence and the requirements of international standards for assessing and improving the quality of pumped water on pumping systems and other hydraulic structures [17-25].

The practical significance of the research results is based on the developed methods of hydraulic calculation of the flow in the flow section of the pumps, the assessment of reliability during operation under various conditions of the quality of the pumped water, and the criteria of its state.

Recommendations for the use of new methods for calculating their main elements in operation in structures and hydromechanical equipment have been introduced at the stations of the Amubukhara canals to increase the service life of pumping units and save resources.

To improve the safety and sustainable operation of PS, it is recommended to: develop regulatory documents that determine the properties of water, which do not lead to wear of equipment and destruction of materials; a methodology for a comprehensive assessment of the degree of risk from the impact of a resource of inappropriate quality during the operation of the PS [26-43].

\section{References}

1. Uralov B.R., Mamazhanov M., Glovatsky O.Ya. Optimization of operating modes of water supply and drainage structures of large pumping stations // Proceedings of the VI International Scientific and Practical Conference "Problems of Science and Education in Modern Conditions" pp.280-283, Shymkent (2009).

2. Glovatsky O. Ya., Ergashev R.R. Some environmental aspects of energy-saving modes of reclamation pumping stations //use of water and land resources and environmental problems in the EECCA region, pp. 151-155, (2011)

3. O.Ya.Glovatsky, F.Zh.Nosirov, Sh.R.Rustamov main ways to reduce the consumption of energy resources in the water sector // Problems of energy and resources. -T, -. pp. 45-50, (2013)

4. Ergashev R.R., New aspects of reliability function of irrigation pumping stations. //European Sciencce review Scientific journal Austria, Vienna. № 1-2, pp.247249(05.00.00;№ 3), (2017).

5. Glovatsky O.Ya., Ergashev R.R., Rustamov Sh.R. Increased operating reliability and water-saving irrigation pumping stations, Water resources and water use. -Astana, №3, - pp. 37-40. (2015).

6. Rustamov Sh. R., Nasirova N. R. Constructive peculiarities of modernized centrifugal pump, European science review, № 3-4, Vienna. pp-278-280, (2018).

7. Bakir F., Kouidri S., Belamri T., and Rey R., "On a general method of unsteady potential calculation applied to the compression stages of a turbo machine-Part I: Theoretical approach," Journal of Fluids Engineering, 123, № 4, pp. 780-786, (2001)

8. Nasrulin A.B., Mukhammadiev M.M. Theoretical foundations of hydroecological monitoring of hydraulic structures for the introduction of new innovative approaches: GIS technologies, remote sensing, water and energy saving technologies, International scientific and practical conference "Water for Sustainable Development of Central 
Asia", March 23-24, 2018. Dushanbe, Republic of Tajikistan Ed. "PROMEXPO", Pp. 388-393, (2018).

9. Glovatsky, O., Ergashev, R., Nasirova, N., Kholbutaev, B., Khusanbayeva, K. Estimation of the forecast of pump ready rate for reclamation systems, IOP Conference Series: Materials Science and Engineering, 1030(1), 012115, (2021)

10. Ergashev, R., Ismoilov, N., Nasirova, N., Khusanbayeva, K., Nazarov, O. Technology of water supply to water inlets of pumping stations, IOP Conference Series: Materials Science and Engineering, 1030(1), 012156, (2021)

11. Ergashev, R., Azizov, O., Dehkanova, N., Bozorov, A. Development of energy-saving modes of irrigation pump stations, IOP Conference Series: Materials Science and Engineering, 883(1), 012017, (2020)

12. Ergashev, R., Bekchanov, F., Akmalov, Sh., Shodiev, B., Kholbutaev, B. New methods for geoinformation systems of tests and analysis of causes of failure elements of pumping stations, IOP Conference Series: Materials Science and Engineering, 883(1), 012015, (2020)

13. Bekchanov, F., Ergashev, R., Mavlanov, T., Glovatskiy, O. Mathematical model of vibrating air pump unit, E3S Web of Conferences, 97, 05045, (2019)

14. Glovatskii, O.Ya., Ergashev, R.R., Bekchanov, F.A., Sharipov, S.M. Hybrid installations in pumping stations based on the use of renewable energy sources, Applied Solar Energy (English translation of Geliotekhnika), 48(4), pp. 266-268, (2012)

15. Shaazizov F, Uralov B, Shukurov E and Nasrulin A (2019) Development of the computerized decision-making support system for the prevention and revealing of dangerous zones of flooding (E3S Web of Conferences 97 FORM-2019 05040 (2019) https://doi.org/10.1051/e3sconf/20199705040).

16. Clark H. McI., "Particle velocity and size effects in laboratory slurry erosion measurements or do you know what your particles are doing", Tribology International, Vol. 35, pp 617-624, (2002).

17. Zhou Weidong, Zhao Zhimei, Lee T. S. and Winoto S. H, , "Investigation of flow through centrifugal pump impellers using computational fluid dynamics", International Journal of Rotating Machinery, Vol. 9, Issue 1, pp 49-61, (2003).

18. Hamed Awatef A., Tabakoff Widen, Rivir Richard B., Das Kaushik, Arora Puneet, , "Turbine blade surface deterioration by erosion", Journal of Turbomachinery, July Vol 127, Issue 3, pp. 445-452, (2002).

19. Gandhi B.K, Singh S. N., Seshadri V. 2001, "Performance characteristics of centrifugal slurry pumps", American Society of Mechanical Engineers, Journal of Fluids Engineering (J Fluid Eng-T ASME), Vol. 123, pp 271-280.

20. Rajesh J. John, Bijwe J., Venkataraman B., Tewari U.S., "Effect of impinging velocity on the erosive wear behaviour of polyamides", Tribology International Vol. 37 , pp 219-226, (2004).

21. Wang Yao, Zuo Ming J., and Fan Xianfeng 2005, "Design of an experimental system for wear asssessment of slurry pumps", Proceeding of the 2nd CDEN conference, Kananaskis, University of Calgary, (2005).

22. Ivanenko Yu.G., Lobanov G.L. A numerical method for solving differential equations for the characteristics of unsteady water flow in open channels, Universities of the North Caucasus. region. Tech. science. 1. pp.56-60, Russia, (2000).

23. D.R.Bazarov, F.K.Artikbekova, Z. Urazmukhamedova System hydrodynamic equations used in mathematical modeling of water flow in canals in the system of pumping stations, Jurnal Irrigatsiya va Melioratsiya, 2(16) pp.20-23, Tashkent, (2019) 
24. Gandhi B K., Borse Satish V. "Nominal particle size of multi-sized particulate slurries for evaluation of erosion wear and effect of fine particles", Journal of Wear, 257, pp 73-79, (2004).

25. Nasrulin A.B., Zhuraev S.R., Saidov F.S. Study of the influence of hydrological and hydraulic parameters on the operating mode of pumping stations, Intellectual salohiyat tarakkiyot mesoni, Republican collection of scientific papers, pp. 302-306, Tashkent (2018)

26. Zharkovskii A.A., Zhurkin, N., Donskoj, A. Numeric modeling and estimating the performance characteristics of a pneumatic driven high pressure pump (2018) MATEC Web of Conferences, 245, article № 09014, DOI: 10.1051/matecconf/201824509014.

27. Bazarov D., Vatin N., Obidov B., and Vokhidov O. Hydrodynamic effects of the flow on the slab of the stand in the presence of cavitation. IOP Conf. Ser. Mater. Sci. Eng. 1030, 012110 (2021).

28. Krutov A., Choriev R., Norkulov B., Mavlyanova D. and Shomurodov A. Mathematical modelling of bottom deformations in the kinematic wave approximation. IOP Conf. Ser. Mater. Sci. Eng. 1030, 012147 (2021).

29. Bazarov D., Markova I., Norkulov B. and Vokhidov O. Hydraulic aspects of the layout of head structures during water intake from lowland rivers. IOP Conf. Ser. Mater. Sci. Eng. 1015, 012041 (2021).

30. Obidov B., Vokhidov O., Tadjieva D., Kurbanova, U., Isakov A. Hydrodynamic effects on the flow elements of the downstream devices in the presence of cavitation. IOP Conf. Ser. Mater. Sci. Eng. 1030, 012114 (2021).

31. Bazarov D., Markova I., Sultanov S. and Kattakulov F. Dynamics of the hydraulic and alluvial regime of the lower reaches of the Amudarya after the commissioning of the Takhiatash and Tuyamuyun hydrosystems. IOP Conf. Ser. Mater. Sci. Eng. 1030, 012110 (2021).

32. Krutov A., Norkulov B., Uljaev F., and Jamalov F. Results of a numerical study of currents in the vicinity of a damless water intake. IOP Conf. Ser. Mater. Sci. Eng. 1030, 012121 (2021).

33. Bazarov D. and Vokhidov O. Extinguishing Excess Flow Energy in Spillway Structures. In book: Proceedings of EECE 2020, LNCE 150, pp. 535-545, (2021) DOI: 10.1007/978-3-030-72404-7_52

34. Krutov A., Norkulov B., Mavlyanova D. Simulation of spreading of non-conservative passive substances in water bodies. IOP Conf. Ser. Mater. Sci. Eng. 883(1), 012028 (2020)

35. Bazarov D., Markova I., Norkulov B., Isabaev K., Sapaeva M. Operational efficiency of water damless intake. IOP Conf. Ser. Mater. Sci. Eng. 869(7), 072051, (2020)

36. Krutov A., Norkulov B., Artikbekova F., Nurmatov P. Optimal location of an intake at a reservoir prone to salt diffusion. IOP Conf. Ser. Mater. Sci. Eng. 869(7), 072020, (2020)

37. Krutov A., Norkulov B., Nurmatov P., Mirzaev M. Applicability of zero-dimensional equations to forecast nonconservative components concentration in water bodies. IOP Conf. Ser. Mater. Sci. Eng. 883(1), 012028 (2020)

38. Bazarov D., Norkulov B., Vokhidov O., Uljaev F., Ishankulov, Z. Two-dimensional flow movement in the area of protective regulatory structures. IOP Conf. Ser. Mater. Sci. Eng. 890, 012162 (2020)

39. Shokirov B., Norkulov B., Nishanbaev Kh., Khurazbaev M., Nazarov B. Computer simulation of channel processes. E3S Web of Conferences, 97, 05012, (2019) 
40. Shomayramov, M., Norkulov B., Rakhmanov J., Tadjiyeva D., Suyunov J. Experimental researches of hydraulic vacuum breakdown devices of siphon outlets of pumping stations. E3S Web of Conferences, 97, 05009, (2019)

41. Matyakubov B., Begmatov I., Raimova I. and Teplova G. Factors for the efficient use of water distribution facilities. IOP Conf. Ser. Mater. Sci. Eng. 883, 012025 (2020).

42. Uralov B., Rakhmatov N., Khidirov S., Uljaev F., Raimova I. Hydraulic modes of damless water intake. IOP Conf. Ser. Mater. Sci. Eng. 1030(1), 012123 (2021)

43. Bazarov D., Markova I., Raimova I., Sultanov Sh. Water flow motion in the vehicle of main channels. IOP Conf. Ser. Mater. Sci. Eng. 883, 012025 (2020). 